\title{
Study of Indoor Air Quality of Kitchens of Rural Area's in Lucknow
}

\author{
AAKANKSHA $^{* 1}$, RATNA KATIYAR ${ }^{1}$ and S.K.RASTOGI ${ }^{2}$ \\ ${ }^{1}$ Department of Botany, Lucknow University, Lucknow- 226007, India. \\ ${ }^{2}$ Ex. Emeritus Scientist, I.I.T.R., Lucknow-226001, India.
}

http://dx.doi.org/10.12944/CWE.9.2.37

(Received: June 18, 2014; Accepted: July 11, 2014)

\begin{abstract}
Study deals with the assessment of Indoor Air Quality (IAQ) in terms of Particulate matter, Gaseous pollutants, Polycyclic Aromatic Hydrocarbons (PAH) during domestic combustions of biofuels (i.e. Fire wood, animal dung and Crop residues) in the cooking and non-cooking area of rural kitchens of the rural suburbs of Lucknow (North India). The indoor air samples of kitchens when analyzed for various pollutants, revealed very high concentrations of $\mathrm{CO}, \mathrm{CO}_{2}, \mathrm{NO}_{2}$ and $\mathrm{SO}_{2}$ in cooking area (kitchen area) as compared to non-cooking area (living area). Burning of biofuels (Fire wood, animal dung and Crop residues) produced highest emission of $\mathrm{PAH}$. Increment in PAH level was found in the cooking area (kitchen area) as compared to PAH level in the non-cooking area. The concentration of $\mathrm{PM}_{10}$ in the indoor air sample was 3.7 times more than that found in the living area. Similarly, the concentration of $\mathrm{PM}_{2.5}$ was four times higher in kitchens using biomass during cooking hours.
\end{abstract}

Key words: Indoor air quality, Domestic cooking, Rural women, Biomass fuel.

\section{INTRODUCTION}

In developing countries the problem of indoor air pollution is increasing at an alarming rate. In rural areas of India, the most important indoor air pollutants are combustion products of unprocessed solid biomass fuels used by the poor rural folk for domestic cooking (ICMR Bulletin, 2001). Approximately half of the world's population and up to $90 \%$ of rural households in developing countries still rely on unprocessed biomass fuels such as wood, dung and crop residues (Bruce et al., 2000). A recent report of the world Health Organization (WHO, 2005) asserts the rule of 1000 which states that a pollutant released indoors is one thousand times more likely to reach peoples lung than a pollutant released outdoors. It has been estimated that about half a million women and children die each year from indoor air pollution in India (Smith, 2000). Biomass fuels viz. animal dung, crop residues and wood, which are the most hazardous fuels, are used mostly by very poor rural women for cooking. It has been estimated that these fuels on combustion release at least 50 times more noxious pollutants than LPG (Smith, 2003).

The biofuels are not burnt completely and release complex mixtures of organic compounds which include suspended particulate matter (SPM), Carbon Monoxide (CO), Poly Organic Material (POM), Polycyclic Aromatic Hydrocarbons (PAH), and intrinsic contaminants such as sulphur, and trace metals etc. Incomplete combustion of biofuels produces $\mathrm{CO}$. use of biofuels poses serious disease burden among Indians as compared to other countries (Smith, 2000). While during the use of liquid petroleum gas (LPG) a negligible amount of $\mathrm{CO}$ is released. A study by the National Institute of Occupational Health $(\mathrm{NIOH}, 1995)$ reported indoor air CO levels of 144, 156, 94, 108 and $14 \mathrm{mg} / \mathrm{m}^{3}$ during cooking by dung, wood, coal, kerosene and LPG respectively. The gaseous by products such as sulfur dioxide $\left(\mathrm{SO}_{2}\right)$, nitrogen dioxide $\left(\mathrm{NO}_{2}\right)$, Ozone $\left(\mathrm{O}_{3}\right)$ have been the most implicated pollutants 
found in indoor air due to combustion of biofuels (Devalia et al., 1997; Davlis et al., 2003 and Rios et al., 2004).

Aim of the study was to report the findings of indoor air quality (IAQ) of the rural households using different biofuels viz. firewood, animal dung and crop residues in terms of particulate matter as the primary pollutant, gaseous and other particulate products at two sites i.e. Cooking area (kitchen area) and Non-Cooking area (living area) as most of the rural domestic cooking is done in these areas.

\section{Methodology}

The indoor air samples from cooking area (kitchen area) and non-cooking area (living area) were collected during cooking and non-cooking times from nearly 30 households situated in rural suburbs of Lucknow (North India). The households in the study group used earthen chullahs. Personal samplers were installed in these areas for monitoring purposes. For respirable dust measurements the samples were collected by drawing air through battery operated constant flow pumps.

The concentration of $\mathrm{PM}_{10}$ in cooking area and non-cooking area were measured by portable, real time aerosol monitor (Dust Track TM, model 8520, TSI Inc, MN, USA). The apparatus contains $10 \mathrm{~mm}$ nylon Dor-Oliver cyclone, operates at a flow rate of 1.7 liters/minute and measures particles load in the concentration range of $10 \mathrm{ig}-100 \mathrm{mg} / \mathrm{m}^{3}$. Since the biomass using women, cook in a sitting posture at 2-3 feet away from the open chullah, the monitor was placed in the breathing zone of the women cooking at 2.5 feet above the floor level on a wooden stool, 3 feet away from the chullah. Measurements of $\mathrm{CO}$, $\mathrm{CO}_{2}, \mathrm{PM}_{2.5}, \mathrm{SO}_{2}, \mathrm{NO}_{2}$ and $\mathrm{PAH}$ were monitored and analyzed using HPLC/FLD (High Performance Liquid Chromatography/Fluorescent Lumen Devices) and UV (Ultraviolet) during cooking and non-cooking area of indoor air. These PAH or polynuclic aromatics (PNA) are the principal pollutants from incomplete combustion which are of special interest due to their toxicity.

\section{RESULTS}

Burning of biofuels resulted indoor smoke leading to particulate pollution. The indoor air during cooking hours showed significantly higher concentration of gaseous pollutants i.e. $\mathrm{CO}, \mathrm{CO}_{2}$, $\mathrm{SO}_{2}$ and $\mathrm{NO}_{2}$ in the indoor air (kitchen area) during cooking hours with the highest values at breathing level is depicted in Table-1, Fig-1. High concentration of $\mathrm{CO}_{2}$ and $\mathrm{CO}$ release was observed in cooking area compared to $\mathrm{NO}_{2}$ and $\mathrm{SO}_{2}$ release during cooking hours. Data clearly depicts that biofuels burning released more of $\mathrm{NO}_{2}$ compared to $\mathrm{SO}_{2}$ (Fig-1). Burning of wood fuel produced the highest emission of PAH due to intensive use of biofuels for domestic combustion. The PAH level was found to be in the range $395-1157 \mu \mathrm{g} / \mathrm{m}^{3}$, compared to $62.3-127.5 \mu \mathrm{g} /$ $\mathrm{m}^{3}$ in outdoor air (Table-2, Fig-2).

The concentration of $\mathrm{PM}_{10}, \mathrm{PM}_{2.5}$ in cooking as well as non-cooking area during cooking hours is depicted in Fig-3 and 4 respectively. Concentration of $\mathrm{PM}_{10}$ was significantly 3.7 times more in kitchen area as compared to non-cooking area during cooking hours $(P<0.001)$. Even during the non cooking hours, $\mathrm{PM}_{10}$ level in cooking area was significantly more than double when compared to non-cooking area i.e. living area (736 vs. $\left.198 \mathrm{ig} / \mathrm{m}^{3}, \mathrm{P}<0.001\right)$ respectively. Similarly, the concentration of $\mathrm{PM}_{2.5}$ (Fig-4) in biomass using kitchen was three times significantly higher in cooking (367 vs. $121 \mathrm{ig} / \mathrm{m}^{3}$, $\mathrm{P}<0.001$ ) and two times higher in non-cooking area during cooking and non-cooking hours respectively (177 vs. $81 \mathrm{ig} / \mathrm{m}^{3}, \mathrm{P}<0.001$ ).

The concentration of $\mathrm{PM}_{10}$ and $\mathrm{PM}_{2.5}$ during 24 hour monitoring in kitchen and living areas of rural households were found significantly different during cooking and non-cooking hours (Fig-5), including maximum concentration of smoke particles in the environment of indoor kitchens as compared to separate living area.

\section{DISCUSSION}

Kitchen measurements of $\mathrm{CO}, \mathrm{CO}_{2}, \mathrm{NO}_{2}$ and $\mathrm{SO}_{2}$ and the respiratory particulate matter (RSPM, 2.5i and the ultrafine particles (UFP) (size range 0.007 to $0.1 \mathrm{im}$ ) in the indoor environment emitted by the combination of biofuels during domestic cooking used by the rural women folk studied in this survey are comparable to a number of other similar studies (Naeher et al., 2000; Smith et al., 2003; Ellegard, 2007; Dockery and Pope, 2009). 
Although it is difficult to fully compare the current study to the others because each deals with different cooking fuels, different sample durations, techniques and different size of the particulate pollution. The levels of classical air pollutants such as $\mathrm{CO}, \mathrm{CO}_{2}$, $\mathrm{NO}_{2}$, and $\mathrm{SO}_{2}$ were found to be significantly higher both in the breathing zone i.e. cooking area near the chullah and also in the indoor ambient air i.e. non-cooking area during cooking using biofuels in comparison to TLVs (Threshold Limit Value) laid down by National Ambient Air Quality Standard (NAAQS, 2000), American Council Of Government Industrial Hygienists (ACGIH, 1983) and United Nation Environmental Protection (UNEP, 1997). The high concentration of these gases is considered to be the major source of respiratory and cardiac mortality among the exposed rural women, their families including new born infants. The epidemiological studies (Mac Nee et al., 2002; Mann et al., 2004; Kreuter, 2004) have shown that the inhalation of the combustible products from biomass fuels can exacerbate the outgoing disease processes in the exposed rural women. Alarming rate of increase in $\mathrm{PM}_{10}$ and $\mathrm{PM}_{2.5}$ has been observed by several researchers which is detrimental for health of living beings. Today, the focus is on $\mathrm{PM}_{2.5}$ emission resulting from combustion and its implications for air quality and human health are linked to the major etiological factor for indoor air pollution (WHO, 2000; Akinson et al., 2001).

Significantly high emission of the $\mathrm{PAH}$ in the Indian rural kitchens observed could be due to several factors during combustion of biofuels. The $\mathrm{PAH}$ are the principal pollutants, which are of special interest due to their toxicity, carcinogenicity and imposing ubiquitous pressure to the environment is primarily produced due to incomplete combustion of biofuels during domestic cooking. The other studies on PAH emission from combustion of biofuels indicated its intensive use, leading to high emission factors of $\mathrm{PAH}$ which is probably related to the high volatile content of biofuels, which commonly correlates to higher possibility of incomplete burning

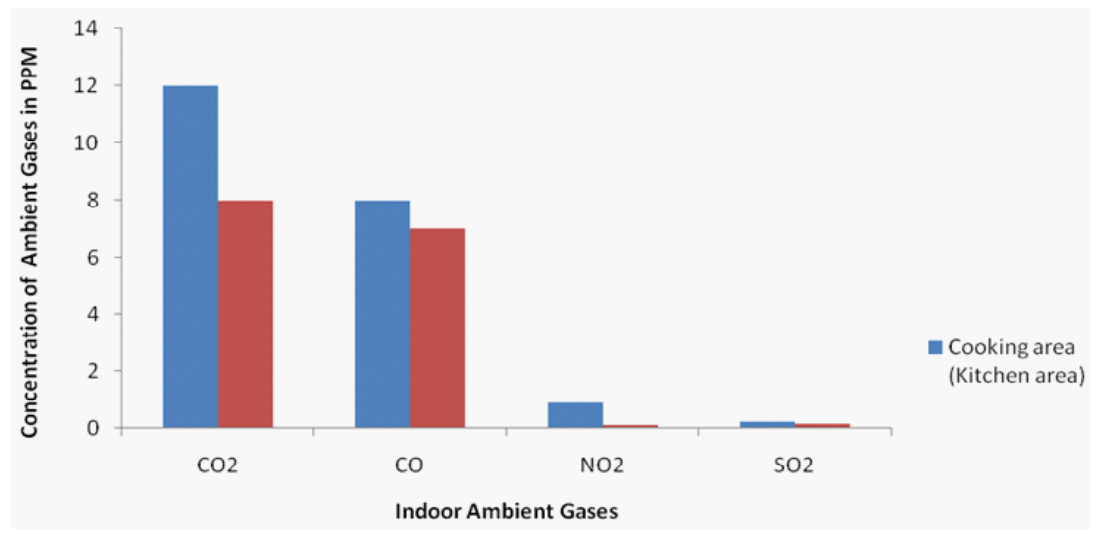

Fig.1: Gaseous pollutants in the indoor ambient air of kitchen area and living area

Table. 1: Concentration of air- borne gases (ppm) released during cooking using biofuels in rural area

\begin{tabular}{|c|c|c|c|c|}
\hline \multirow{2}{*}{$\begin{array}{l}\text { Pollutants } \\
\text { (ppm) }\end{array}$} & \multicolumn{2}{|c|}{$\begin{array}{l}\text { Cooking area } \\
\text { (kitchen area) }\end{array}$} & \multicolumn{2}{|c|}{$\begin{array}{l}\text { Non-cooking area } \\
\text { (living area) }\end{array}$} \\
\hline & Mean & $\overline{\text { Range }}$ & Mean & Range \\
\hline $\mathrm{CO}_{2}$ & $12.00 \pm 3.40$ & $9.00-44.50$ & $8.09 \pm 2.65$ & $6.80-30.40$ \\
\hline $\mathrm{CO}$ & $8.40 \pm 3.30$ & $6.80-31.20$ & $4.40 \pm 2.10$ & $4.00-18.60$ \\
\hline $\mathrm{NO}_{2}$ & $0.90 \pm 0.11$ & $0.60-0.99$ & $0.10 \pm 0.01$ & $0.05-0.21$ \\
\hline $\mathrm{SO}_{2}$ & $0.25 \pm 0.10$ & $0.21-0.40$ & $0.15 \pm 0.04$ & $0.12-0.21$ \\
\hline
\end{tabular}

Values are means of replicates \pm SD. 
(Oanh et al., 2005). Poor kitchen ventilation is an important factor for high concentration of $\mathrm{PAH}$ in rural Indian kitchens. We found very poor kitchen ventilation in most of the rural houses surveyed by us during the study. There were no chimneys or exhausts in any of the rural kitchens. This in together with low efficiency cook stoves or chullahs and large

Table. 2: Concentration of PAH $\left(\mu \mathrm{g} / \mathrm{m}^{3}\right)$ in cooking and non-cooking area

\begin{tabular}{lcc}
\hline & \multicolumn{2}{c}{ PAH concentration $\left(\mu \mathrm{g} / \mathrm{m}^{3}\right)$} \\
\cline { 2 - 3 } & $\begin{array}{c}\text { Inside the kitchen } \\
\text { (cooking area) }\end{array}$ & $\begin{array}{c}\text { Living area } \\
\text { (non-cooking area) }\end{array}$ \\
\hline Mean & $957.0 \pm 100.4$ & $157.6 \pm 24.6$ \\
Range & $395.0-1157.0$ & $62.3-127.5$ \\
\hline
\end{tabular}

Values are means of replicates \pm SD. amounts of biofuels usage resulted in serious indoor air pollution thus leading to high levels of $\mathrm{PAH}$ (World Health Organization (WHO, 1999); United States Environmental Protection Agency (USEPA, 1997).

High values of $\mathrm{PAH}, \mathrm{CO}, \mathrm{NO}_{2}, \mathrm{PM}$ were accounted at sitting breathing zone when biomass (dung cake, fuel wood and other agricultural residues) were used. This accounts for more than $90 \%$ of the total fuel consumption in rural areas, during domestic cooking. Several studies have reported that in rural houses of developing countries the $\mathrm{PAH}$ level was found to be in the range $100-10,000 \mathrm{ng} / \mathrm{m}^{3}$ (Khandpal et al., 1995; Gupta et al., 1998). The magnitude of air pollution from biomass smoke can be judged from the report that concentration of RSPM in Indian kitchens is thirty times of the WHO guideline while its outdoor concentration is two and half times of the

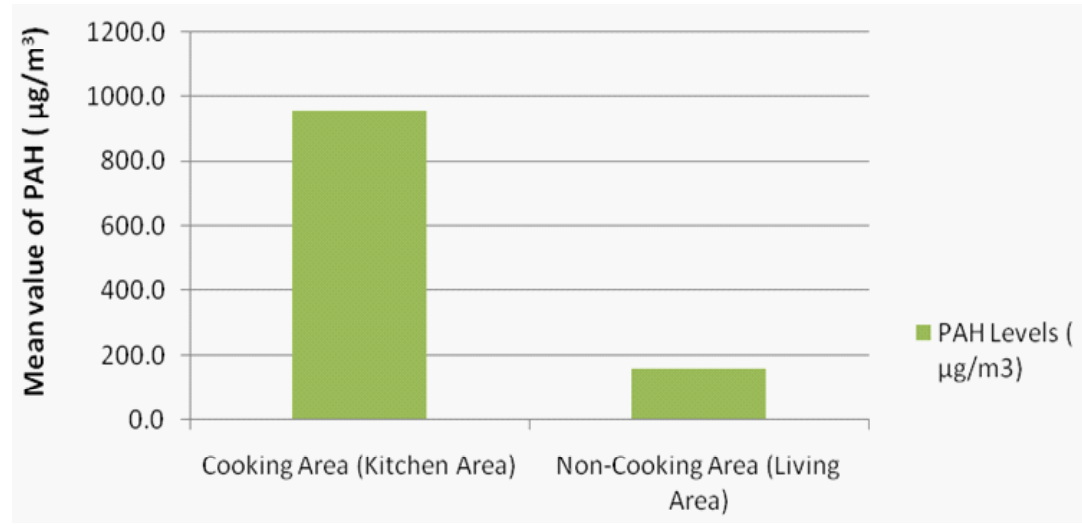

Fig.2: Mean value of PAH in Cooking Area (Kitchen Area) and Non-Cooking Area (Living Area) using biofuels in the rural kitchens.

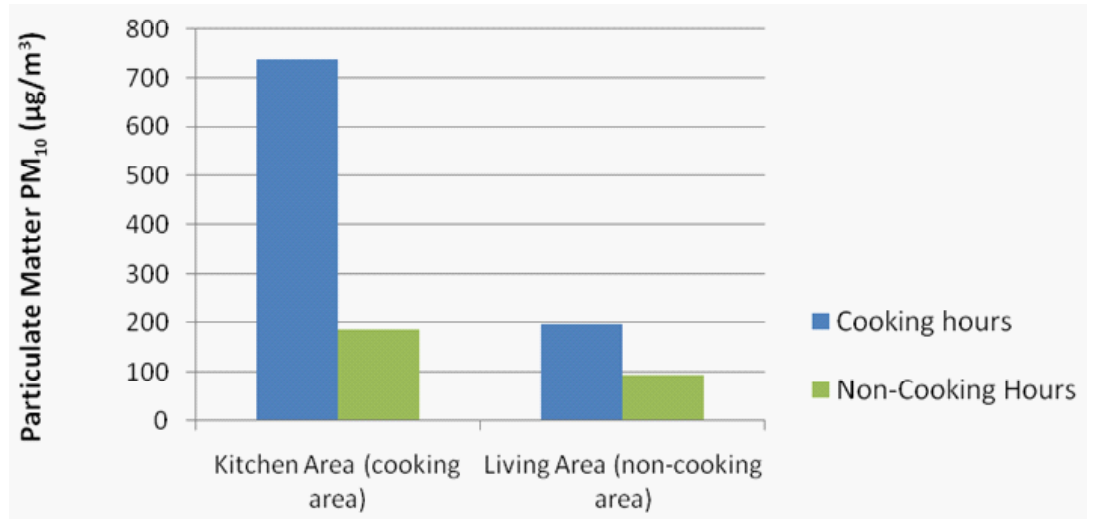

Fig.3: Particulate Matter $\left(\mathrm{PM}_{10}\right)$ in Cooking hours (Kitchen area) and Non-Cooking (Living area) in Rural kitchens using biomass. 


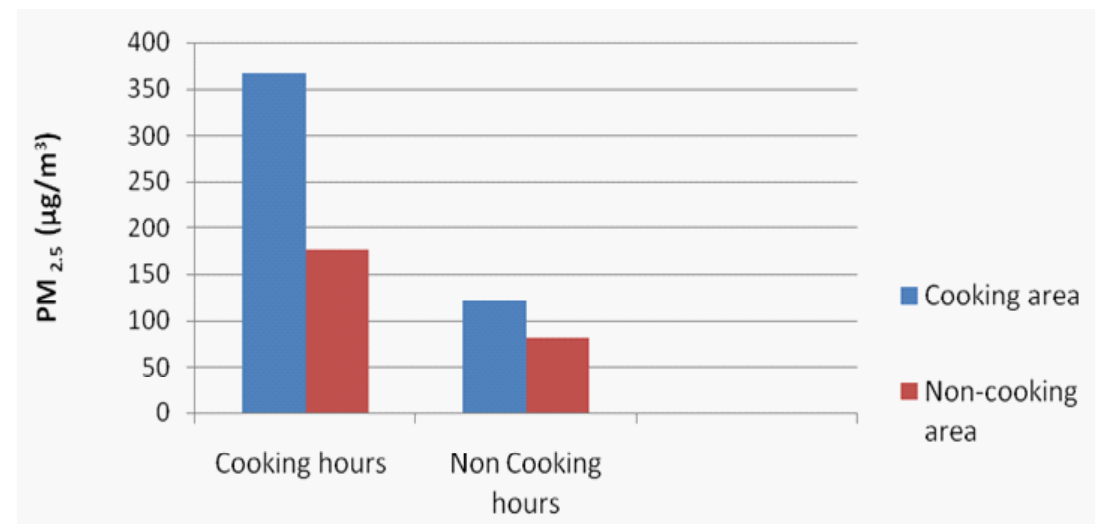

Fig.4: Particulate Matter $\left(\mathrm{PM}_{2.5}\right)$ in rural kitchens during cooking and non-cooking hours using biomass as fuel.

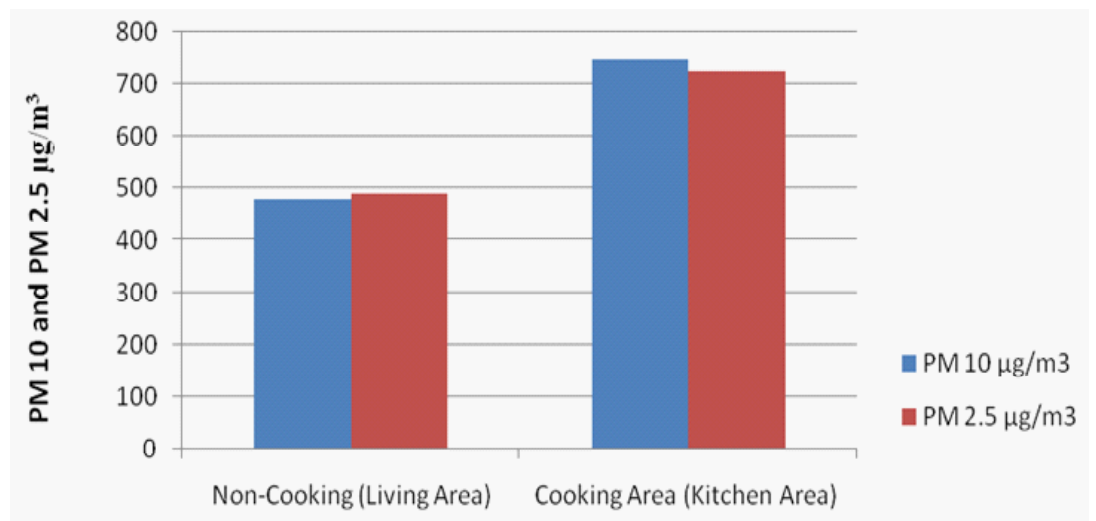

Fig.5: Concentration of $\mathrm{PM}_{2.5}$ and $\mathrm{PM}_{10}$ during 24 hour monitoring in non-cooking (living area) and cooking area (kitchen area).

guideline of Tata Energy Research Institute (TERI, 1997; WHO, 1999). Engle et al., (1997) observed that the people of the developing countries are typically exposed to very high levels of indoor air pollution for 3 to 4 hours a day. Since it is always the women who cook daily household meals, their exposure is much higher than men's (Behera et al., 2001).
It can be concluded on the basis of survey study that there is significant health risk associated with increased concentration of gaseous pollutants and suspended particulates including $\mathrm{PAH}$. Our study, therefore, recommends more stringent bio monitoring studies and use of high efficiency cooking devices to cut down the emission of toxic chemicals, gases etc during combustion of biofuels in Indian rural kitchens along with better kitchen ventilation.

\section{REFERENCES}

1. ACGIH, Encyclopedia of Occupational Health and Safety. A Technical Report, New - York, USA, 71-75 (1983).

2. Akinson, A.E., Ball, J.C. and Lighty, J.S. Particle characteristics responsible for effects on lung. Res Health Eff Inst, 110: 67-76 (2001).

3. Albalak, R., Keeler, G.J. and Frisancho, A.R.
Assessment of PM10concentrations from domestic biomass fuel combustion in two rural Bolivian highland villages. Environ Sci Technol. 33 : 2505-2509 (2004).

4. Behera, D., Dash, S. and Malik, S. Blood carboxy haemoglobin levels following acute exposure to smoke of biomass fuel. Ind J Med Res, 522-542 (2001). 
5. Bruce, N., Neufeld, L., and Boy, E. Indoor biofuel air pollution and respiratory health. Int. J. Epid., 27: 454-458 (2000).

6. Davelis, O., Dary, J. and Pineda, P. carbon monoxide in dwellings in poor rural areas of Gantemala. Bull Environ. Cont. Toxicol, 26: (2003).

7. Devalia, H.N., Wang, X. and Ding, H. Domestic environment and health of women and children. p 77, TERI Annual Report (1997).

8. Dockery, D.W. and Pope, C.A. Acute respiratory effects of air particulate pollution. Annu Rev Public Health. 15 : 107- 132 (2009).

9. Ellegard, A. Cooking fuel smoke and respiratory symptoms among women in low income areas of Maputo, Environ Health perspect, 104: 980-985 (2007).

10. Engle, P.L., Hurtado and Ruel, M. Smoke exposure of women and young children in highland Guatemala. Human organiz. 56 : 408-417 (1997).

11. Gupta, S., Saksena, S. and Shankar, V.R. Biomass Bioenergy. 14: 547-559 (1998).

12. ICMR Bulletin, Indoor Air pollution in India A major environmental and public health concern. (5), ISSN 0377-4910, May (2001).

13. Khandpal, J.B., Maheswari, R.C. and Khandpal, T.C. Energy Convers. Manage, 36: 1067-1072 (1995).

14. Kreuter, R.O. and Hoylaerts, H.M. Particulate and gaseous emission form wood burning. Environ Sci Technol. 16 (10): 639-645 (2004).

15. MaCNee, J.D., Swartz, R.C. and Movier, G, Biomass fuel combustion and environmental Health. Bull Toxicol. 63: 11-17 (2002).

16. Mann, A., Nemar, M.F. and Hoet, P.H., Size effect of intra tracheally instilled particles on pulmonary inflammation Thrombosis, 186: 38-45 (2004).

17. NAAQS, Central Pollution Control Board (CPCB), New Delhi, India, Report No. 98: 16-21 (2000).
18. Naeher, L.P., Smith, K.R. and Leaderer, B.P. Indoor and outdoor PM 2.5 and $\mathrm{CO}$ in high and low density Gautemalan Villages. J Exp Anal \& Environ Epid. 10: 544-551 (2000).

19. NIOH, Domestic source of air pollution and its effects on respiratory system of housewives of Ahmedabad. 32: (1995).

20. Oanh, N.T.K., Reutergardh, L.B. and Dung, N.T. Emission of PAN and particulate matter from domestic combustion of selected fuels. Environ Sci. Technol. 33: 2703-2709 (2005).

21. Rios, J., Vedal, S. and Pare, P. Exposure to biomass smoke and chronic airway disease in Mexican women. Am. J Respir. Crit Care Med, 154: 701-706 (2004).

22. Smith, K.R., Indoor air pollution implicated in alarming health problems. In: Indoor Air Pollution Energy and Health for poor. News Letter, 1: (2003)

23. Smith, K.R., Samet, J.M., Romien, I. Indoor air pollution in developing countries and acute respiratory infections in children. Thorax, 55 : 518-532 (2000).

24. TERI, Biomass Energy Systems, Ramana V., Srinivas SN, TERI, New Delhi, India (1997).

25. UNEP, Maximum allowable concentration and safe exposure levels of harmful substances in the environment. Moscow centre for International Profeel, GKNY (1997).

26. USEPA, Depositon of air pollutants to the Great Lakes, First Report to congress, EPA 453/ R93-055 (1997).

27. WHO, Guidelines for Air Quality, WHO, Geneva Switzerland (1999).

28. WHO, Indoor air pollution form Biomass fuel Report of a WHO consultations, June, WHO/ PEP/ 92.3B, Geneva, Switzerland (1999).

29. WHO, Guidelines for Air quality WHO publications, Geneva, Switzerland (2000).

30. WHO, Heath effects of chronic exposure to smoke from biomass fuel burning in rural areas. SE/07/11828 (2005). 